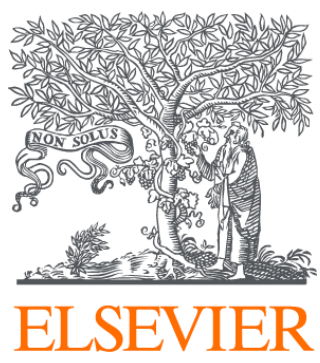

Since January 2020 Elsevier has created a COVID-19 resource centre with free information in English and Mandarin on the novel coronavirus COVID-

19. The COVID-19 resource centre is hosted on Elsevier Connect, the company's public news and information website.

Elsevier hereby grants permission to make all its COVID-19-related research that is available on the COVID-19 resource centre - including this research content - immediately available in PubMed Central and other publicly funded repositories, such as the WHO COVID database with rights for unrestricted research re-use and analyses in any form or by any means with acknowledgement of the original source. These permissions are granted for free by Elsevier for as long as the COVID-19 resource centre remains active. 


\title{
The impact of COVID-19 on air pollution: Evidence from global data
}

\author{
Suborna Barua*, Shobod Deba Nath \\ Department of International Business, University of Dhaka, Dhaka 1000, Bangladesh
}

\section{A R T I C L E I N F O}

\section{Article history:}

Received 18 August 2020

Received in revised form

6 March 2021

Accepted 12 March 2021

Available online 18 March 2021

Handling editor: Cecilia Maria Villas Bôas de Almeida

\section{JEL classification:}

JEL

Q53

I15

Keywords:

COVID-19

Coronavirus

Pollution

CO emissions

Environmental quality

\begin{abstract}
A B S T R A C T
The COVID-19 pandemic is producing significant economic and social cost globally. As a cure or a treatment is yet unavailable, social distancing is considered the key way to prevent it. Mobility restrictions and confinement measures implemented across the world are considered to help reduce air pollution. However, empirical examination of the link between public mobility changes and air pollution during the COVID-19 period remains unavailable. This paper examines the short and long run impacts of mobility changes on carbon monoxide (CO) emissions by employing three dynamic estimators on a panel of 35 countries covering daily data from 15 February to April 17, 2020 - a period when most countries went into strict lockdowns. Findings show a consistent evidence at the all-countries level and across regions that long-run indoor mobility increases reduce CO emissions, while outdoor mobility increases across places such as transit stations, workplaces, grocery \& pharmacies, retail \& recreation, and parks drive up emissions. Among the regions studied, Europe excluding the EU and the UK $(-8.4 \%)$, followed by East Asia and the Pacific $(-4.3 \%)$, sees a larger emissions reduction from increased indoor mobility. While short-run effects are limited in general, emissions in US-Canada respond to indoor and outdoor mobility changes in both the short (1.1\%) and long run $(-1.4 \%)$. Findings overall indicate that reducing unnecessary outdoor mobility could help in maintaining air quality in the post-pandemic world.
\end{abstract}

(C) 2021 Elsevier Ltd. All rights reserved.

\section{Introduction}

The COVID-19 pandemic has forced social and economic activities to freeze across the world, as it becomes truly globalized. A growing amount of studies suggest enormous economic and social cost of the pandemic across the world (Baldwin and deMauro, 2020; Barua and Barua, 2021; Barua, 2020a,b; UNDP 2020; WTO 2020; Nicola et al., 2020). Since a cure and treatment to COVID-19 is yet unavailable, the World Health Organization (WHO) and health system regulators advise social distancing as the main weapon to fight the pandemic (CDC 2020, 6 May; WHO 2020, 29 April). In the strictest forms, social distancing measures may be enforced through a partial or complete nation-wide lockdowns or nation-wide or region-specific mobility restrictions. An increasing amount of discussion suggests that such measures have substantially reduced all kinds of pollutant emissions to the environment driving the air quality up across the world as industrial production, construction and vehicular movement decline dramatically (Le

\footnotetext{
* Corresponding author.

E-mail address: sbarua@du.ac.bd (S. Barua).
}

Quéré et al., 2020; Muhammad et al., 2020; Wang and Su, 2020). For example, emissions in China fell by about 18\% (a cut of $250 \mathrm{~m}$ tonnes) between early February and mid-March 2020 and Europe is forecast to see a reduction of around $390 \mathrm{~m}$ tonnes (Watts 2020, April 9).

However, despite much discussion, empirical examination of a direct link between COVID-19 led social distancing and air pollution remains absent. Some studies provide evidence analyzing trends and patterns of different pollutants and air particulate (e.g., NO2, $\mathrm{CO} 2, \mathrm{SO} 2, \mathrm{CO}, \mathrm{PM} 2.5$ ) releases data during the COVID induced lockdown period as shown in Table 1. The available studies use spatial images and descriptive analysis to show the extent or magnitude of air quality improvements or reductions in pollutant emissions due to COVID-19 led lockdowns and mobility restrictions. However, none of the studies yet shows an empirical and quantitative link between COVID-19 led social distancing measures and pollutant emissions.

Among all the pollutants considered by the existing studies, carbon monoxide $(\mathrm{CO})$ is one of the key that is voraciously emitted by fossil-fuel consumption in everyday human and economic activities such as vehicular movement, industrial activities, power 
Table 1

Literature on the air quality effects of COVID-19.

\begin{tabular}{|c|c|c|c|}
\hline Author (year) & Context & Air quality aspects studied & Methodology \\
\hline Kanniah et al. (2020) & South Asia & $\begin{array}{l}\text { aerosol optical depth; PM10, PM2.5, } \\
\text { NO2, SO2, and CO; }\end{array}$ & Images, descriptive analysis \\
\hline He et al. (2020) & China & Air Quality Index; PM2.5 & Images, event study \\
\hline Le Quéré et al. (2020) & World & $\mathrm{CO} 2$ emissions & Images, descriptive analysis of changes \\
\hline Muhammad et al. (2020) & China & NO2 emissions & Images, descriptive analysis \\
\hline Rume and Islam (2020) & China and India & NO2 and $\mathrm{CO} 2$ emissions & Images, descriptive analysis \\
\hline Islam et al. (2020) & Bangladesh & $\mathrm{NO} 2, \mathrm{SO} 2, \mathrm{CO}$, and $\mathrm{O} 3$ concentrations & Spatiotemporal analysis \\
\hline Cheval et al. (2020) & Selected countries & Aerosol optical depth, NO2 & Images, Descriptive analysis \\
\hline Wang and Su (2020) & China & $\begin{array}{l}\text { PM10, PM2.5, NO2, SO2, and } \mathrm{CO} \\
\text { emissions }\end{array}$ & Images, Descriptive analysis \\
\hline Bashir et al. (2020) & USA & $\begin{array}{l}\text { PM 10, PM 2.5, Sulfur dioxide (SO2), } \\
\text { Volatile organic compounds (VOC), } \\
\text { Carbon monoxide (CO), Nitrogen } \\
\text { dioxide (NO2) and Lead (Pb) }\end{array}$ & Images, Descriptive analysis \\
\hline Lokhandwala and Gautam (2020) & India & Air quality index & Images, Descriptive analysis \\
\hline Bilal et al. (2020) & Germany & $\begin{array}{l}\text { PM2.5, PM10, Ozone (O3), and Nitrogen } \\
\text { dioxide (NO2) }\end{array}$ & Images, Descriptive analysis \\
\hline Gautam (2020) & Selected countries & NO2 emissions & Images, Descriptive analysis \\
\hline
\end{tabular}

Source: authors' developed.

Table 2

Categories of places in worldwide mobility data.

\begin{tabular}{ll}
\hline Place category & Explanation \\
\hline Grocery \& pharmacy & Places like grocery markets, food warehouses, farmers markets, specialty food shops, drug stores, and pharmacies. \\
Parks & Places like local parks, national parks, public beaches, marinas, dog parks, plazas, and public gardens. \\
Workplace & Places where people go for work. \\
Transit stations & Places like public transport hubs such as subway, bus, and train stations. \\
Retail \& recreation & Places like restaurants, cafes, shopping centers, theme parks, museums, libraries, and movie theaters. \\
Residential & Places of residence. \\
\hline
\end{tabular}

Source: authors' developed.

Table 3

Region-wise country grouping of sample countries.

\begin{tabular}{|c|c|}
\hline Major continent group & Region grouping used for analysis \\
\hline Americas & (i) North America (ii) US-Canada, (iii) South America; \\
\hline Europe & (iv) EU countries, (v) EU countries including the UK, (vi) Other Europe countries; \\
\hline Asia & (vii) Middle East and Central Asia (MECA), (viii) East Asia and the Pacific (excluding China) (EAP), (ix) South and Southeast Asia (SSA); \\
\hline Oceania & (xi) Australia-New Zealand (Aus-NZ) \\
\hline
\end{tabular}

Source: authors' developed.

a China is excluded since mobility data on China is unavailable in Google mobility data.

generation, and aviation and travelling (TRB and NRC 2002). CO emissions cause many critical and life-threatening diseases (e.g., asthma, bronchiolitis, and cardiovascular diseases) and pose serious threat to health and lives (TRB and NRC 2002; Penney et al., 2010; Yang et al., 2004). The understanding about how COVID-19 led strict social distancing measures affect air pollution requires a careful assessment on how public mobility changes during the COVID-19 period particularly affect the level of CO emissions.

Environmentalists and researchers are calling this pandemic a "blessing in disguise"- as lockdowns have drastically reduced air pollution (Muhammad et al., 2020). Human activities driven air pollution is normally one of the leading causes of health crisis, inequality, and deaths around the world (Yang and Liu, 2018; Lin and Zhu, 2018; Zhang et al., 2016). The pandemic has caused reduced air pollution as public mobility is halted, airlines being shut down, and other highway transportation being canceled, which gives us the opportunity to breathe in a low carbon air (Monks 2020, April 20). Lockdowns and reduced mobility improves the quality of our surrounding environment significantly, reduced air pollution being the most impactful outcome. Le Quéré et al.
(2020) show that during forced confinement period of COVID-19, daily global $\mathrm{CO} 2$ emissions decreased by $-17 \%$ by early April compared with the mean 2019 levels, and the overall impact on the 2020 annual emissions level depends on the duration of the confinement or lockdowns. The social distancing and lock-down results in reduced environment pollution worldwide in multiple ways. The National Aeronautics and Space Administration (NASA) and the European Space Agency (ESA) report that due to the decreased level of transportation and mainstream industrial and economic activities, the levels of greenhouse gases (GHGs) such as Carbon Dioxide (CO2) and other air pollutants drop sharply in China during the lockdown days in Wuhan, China (Patel 2020, March 5; ESA 2020a, March 19). According to the NASA and the ESA, air pollution in some of the epicenters of COVID-19 such as Wuhan, Italy, Spain and USA etc. declines up to 30\% (Muhammad et al., 2020). The ESA reports that NO2 levels in the European atmosphere decreased by $30-54 \%$ in Paris, Milan, Madrid and Rome (ESA, 2020b, April 16; NASA 2020, April 10). As strict social distancing is enforced and people are confined at homes during lockdowns, coal consumption - a key contributor to air pollution - 
Table 4

Descriptive statistics, all countries.

\begin{tabular}{llllll}
\hline Variable & Obs & Mean & Std. Dev. & Min & Max \\
\hline CO emissions & 2140 & 4.90 & 5.62 & 0.10 & 54.55 \\
Residential mobility & 2193 & 11.55 & 11.94 & -4.00 & 53.00 \\
Transit mobility & 2193 & -31.86 & 31.77 & -95.00 & 18.00 \\
Workplace mobility & 2193 & -23.13 & 29.34 & -92.00 & 56.00 \\
Grocery \& Pharmacy mobility & 2193 & -12.47 & 23.51 & -95.00 & 58.00 \\
Retail \& recreation mobility & 2193 & -30.52 & 32.45 & -96.00 & 30.00 \\
Park mobility & 2193 & -15.84 & 34.69 & -92.00 & 188.00 \\
\hline
\end{tabular}

Source: authors' calculation.

drops by $40 \%$ in the top six power plants in China since the last quarter of 2019 until March (Henriques 2020). The International Energy Agency (IEA) predicts that there will be about 6\% reduction in world's total energy consumption in 2020 causing a drastic fall in CO2 emissions (McGrath 2020, March 6). In major cities across India, the NO2 concentration in the atmosphere of Mumbai and Delhi drops by nearly $40-50 \%$ in comparison to last year in the similar period, according to the ESA (2020c, April 24).

While a growing amount of evidence of reduced air pollution due to lockdowns and reduced public mobility is emerging, an empirical examination of how public mobility changes affects air pollution remains absent. In particular, no study yet provides a direct elasticity measure of the impacts of mobility changes on pollution reductions. Considering the gap, this research empirically examines the quantitative link between public mobility changes and $\mathrm{CO}$ emissions driven air pollution during a COVID-19 period when almost all countries across the world enforce strict lockdown and confinement measures. In other words, the paper produces quantitative estimates of the magnitude and direction impacts of public mobility on $\mathrm{CO}$ emissions. With this aim, the research produces quantitative estimates of how public mobility changes in indoor and outdoor places affect $\mathrm{CO}$ emissions in the long-run and short-run using daily data of 35 countries from 15 February to April 17, 2020. To provide a consistent evidence, impacts are estimated at the world level and across eight regions using three different estimators. Given the unavailability of empirical evidence on the link between mobility changes and CO emissions during a COVID-19 period, the paper offers several significant literature contributions and helps to augment the on-going discussion on the environmental benefits of COVID-19. First, it evidences a quantitative elasticity measure of the impacts of mobility restrictions on $\mathrm{CO}$ emissions across countries at the world level. Second, the impact elasticity measurements separately across the eight regions show the geographic variations in the extent of environmental pollution reductions due to COVID-19; it allows understanding the degree of environmental benefits that can be accrued by countries due to locational differences. Last but not the least, the paper provides novel information on the temporal variations in pollution impacts due to mobility changes by producing separate estimates of the short and long run elasticities. (a): Average $\mathrm{CO}$ emissions across all countries

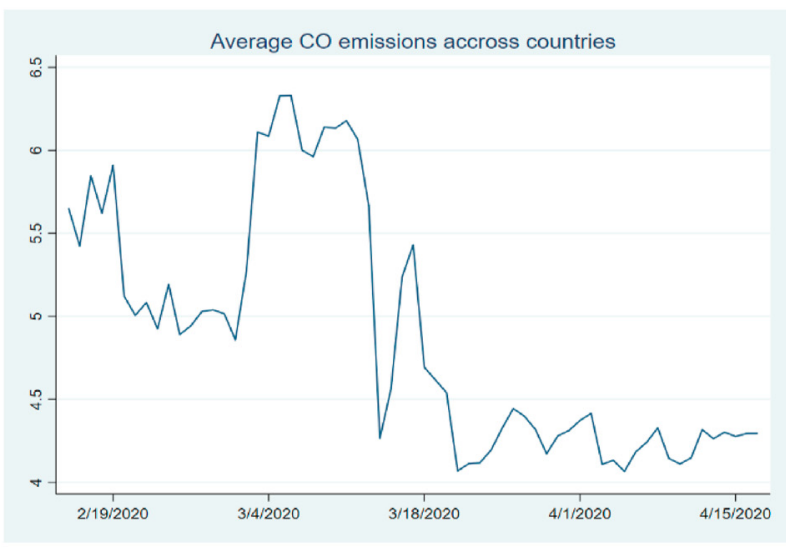

(b): Average $\mathrm{CO}$ emissions by region

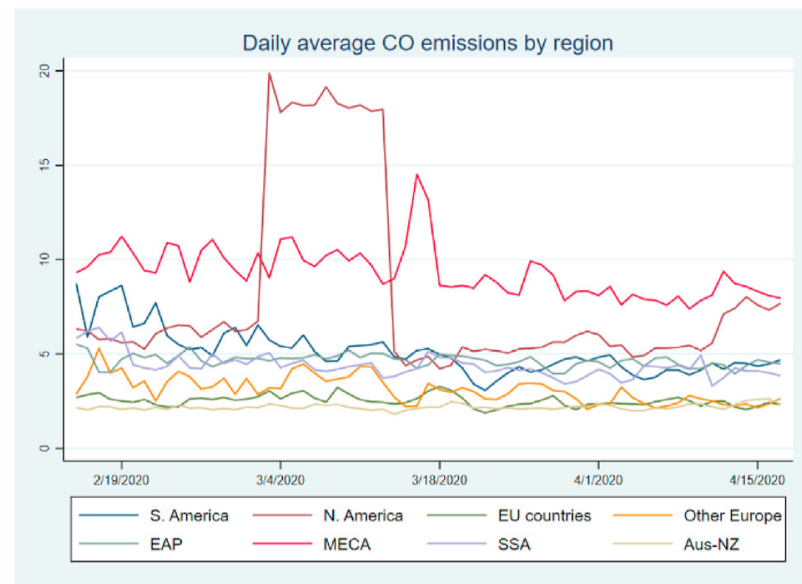

Fig. 1. Average $\mathrm{CO}$ emissions across all countries

Fig. 1(a): Average CO emissions across all countries

Fig. 1(b): Average CO emissions by region

Source: authors' developed based on AQI data used in this research.

\section{Materials and method}

The paper follows a quantitative approach. The following sections outline the data utilized and specifies the methods used in this research.

\subsection{Variable and data}

To examine the effects of public mobility changes on air pollution, the paper uses daily Google mobility data as measures of mobility

Table 5

Correlation matrix, all countries.

\begin{tabular}{|c|c|c|c|c|c|c|c|}
\hline & CO emissions & Resid. mob & Transit mob. & Workpl. mob. & Groc. \& Pharma mob. & Retail \& recr. mob. & Park mob. \\
\hline $\mathrm{CO}$ emissions & 1 & & & & & & \\
\hline Residential mobility & $-0.10 * * *$ & 1 & & & & & \\
\hline Transit mobility & $0.08 * * *$ & $-0.94 * * *$ & 1 & & & & \\
\hline Workplace mobility & $0.10 * * *$ & $-0.95^{* * *}$ & $0.94 * * *$ & 1 & & & \\
\hline Grocery \& Pharmacy mobility & $0.05 * * *$ & $-0.81 * * *$ & $0.83 * * *$ & $0.81 * * *$ & 1 & & \\
\hline Retail \& recreation mobility & $0.11 * * *$ & $-0.92 * * *$ & $0.96 * * *$ & $0.91 * * *$ & $0.87 * * *$ & 1 & \\
\hline Park mobility & 0.01 & $-0.70 * * *$ & $0.68 * * *$ & $0.59 * * *$ & $0.69 * * *$ & $0.74 * * *$ & 1 \\
\hline
\end{tabular}

Source: authors' calculation; levels of significance: $1 \%=* * *, 5 \%=* *$, and $10 \%=*$. 


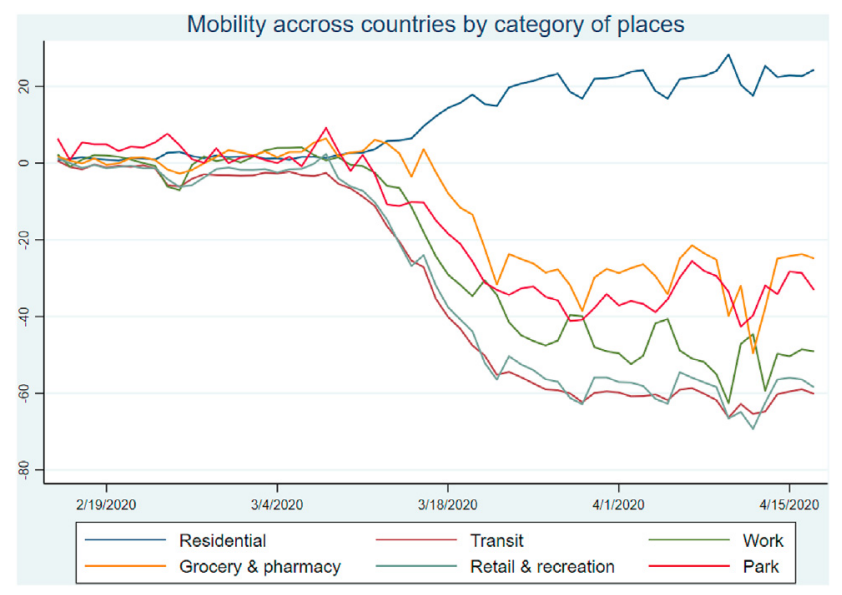

Fig. 2. Average daily mobility changes across all countries by category of places Source: authors' developed based on Google mobility data.
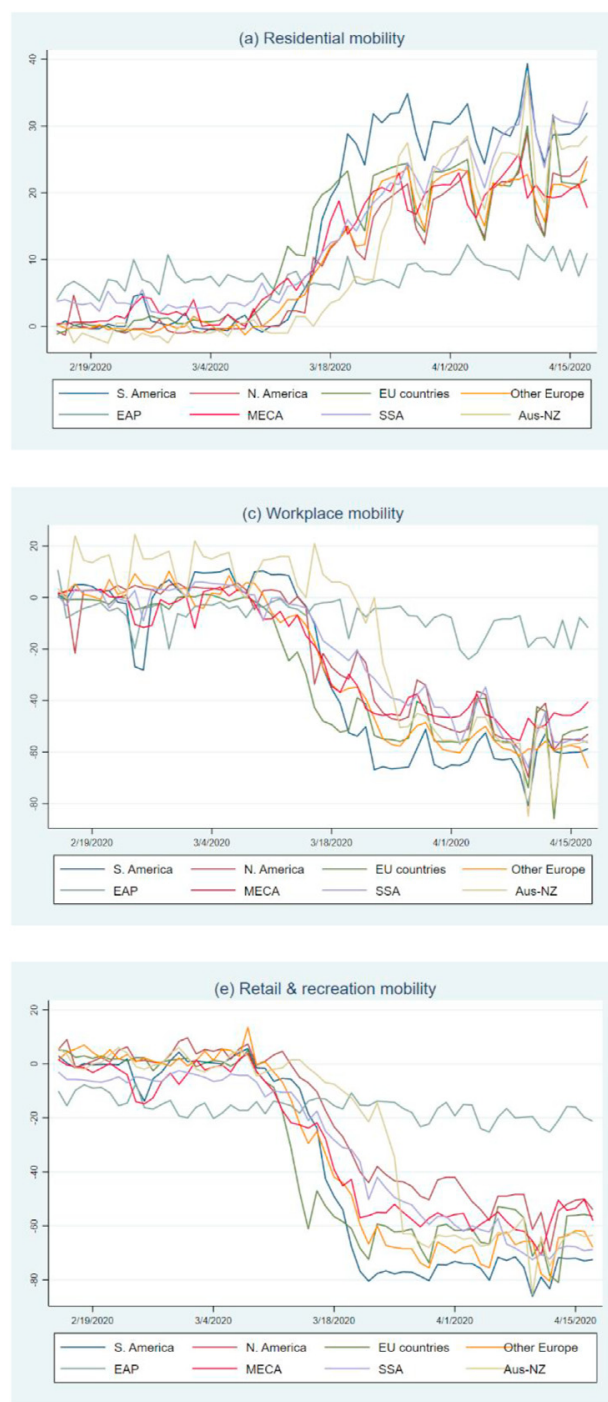

Fig. 3. Region-wise average daily mobility changes by category of places Source: authors' developed based on Google mobility data used in this research. changes and daily carbon monoxide (CO) emissions data published by the World Air Quality Index project during the worldwide strict social distancing and lockdown actions. The research initially considers 128 countries; however, the set of countries common to both dataset limited the number of samples to be evaluated. Furthermore, in the common set of countries, data frequency and dates of many countries for social mobility and $\mathrm{CO}$ emissions cannot be matched between the AQI and Google mobility data. In other words, many countries were on the AQI but not in the Google mobility data and vice versa; similarly, some data for countries that are common cannot be date-matched and also number of available observation for some countries is found too small to be evaluated. After matching data availability and time period commonalities across all countries, 35 countries are finally selected for analysis since they are found to have consistent daily data of AQI and Google mobility records over period of COVID-19 duration from 15 February to April 17, 2020 - a period when almost all countries across the world enforce strict lockdown and confinement measures. A complete list of the countries selected is available in appendix Table A1.
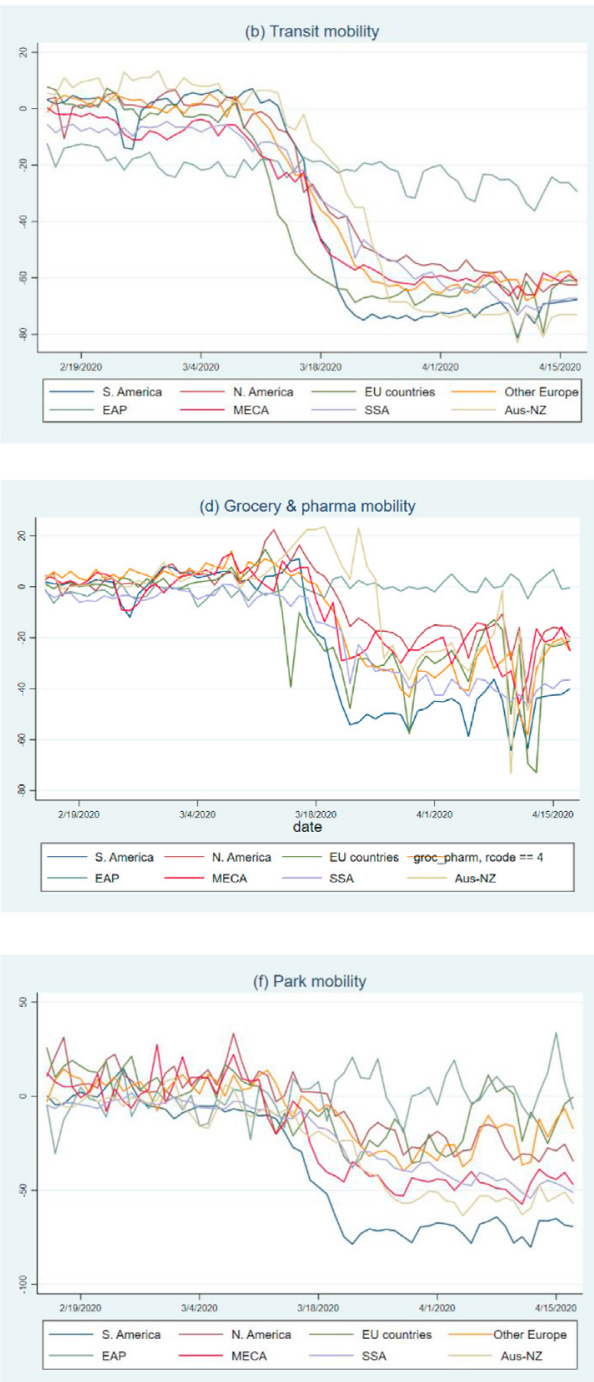
The original World Air Quality Index dataset contains major city-wise median (across several stations) CO emissions daily data for each country measured in parts per million (ppm). All air pollutant emissions species are converted to the US Environmental Protection Agency (EPA) standard (details about the measurement are available at https://aqicn.org). For this research, average of the median $\mathrm{CO}$ values are calculated for each day across the recorded major cities for a country and are used as the measure of $\mathrm{CO}$ emissions in a country on a specific day. On the other hand, data on public mobility patterns across counties at the world level is scarce. Google mobility data is considered the most widely and publicly available and reliable data source for measuring publicly mobility at the country level across a large number of countries of the world. Since this research aims to carry out examinations across regions around the world, Google mobility records provide the best possible data for this purpose. The data are monitored and published by Google and aimed at measuring worldwide social distancing patterns. They record daily changes in public mobility across six categories of places as outlined in Table 2 . The data reflects how visits and length of stay at different places for each day changes compared to a baseline value for that day of the week. The baseline used is the median value, for the corresponding day of the week, during the 5-week period from 3 January - February 6, 2020. . Details about the mobility data are available at Google LLC (2020). Among the six categories of places, all but Residential are outdoor places. Due to the very nature of the data, this research defines Residential category as indoor place and the other five places as outdoor places.

In this research, the effect of mobility changes in each of the six categories of places on CO emissions is separately analyzed. This analysis is carried out in a two-phase process:

- first, at the all-countries level aggregate all 35 countries; and - second, across regions grouping the 35 countries into 8 different regions as shown in Table 3 . A detail list of countries by region is available in appendix Table A1.

\subsection{Specification of model and estimation method}

The paper aims to empirically estimate the short and long run impacts of public mobility changes on $\mathrm{CO}$ emissions during strict COVID-19 restriction days. To do this, the paper uses a panel autoregressive distributed lag model (ARDL)-based framework using the pooled mean-group (PMG) estimator, proposed by Pesaran et al. (1999), Pesaran and Shin (1999), Pesaran and Smith (1995). The primary motivation for using the PMG estimator is that it can identify the long-run cointegrating relationship between the variables of interest and separately produce the long-run and short-run relationships, even if the included variables are in a mixed-order of integration (I(0) and I(1)). The PMG estimator requires specifying a dependent variable as a function of the independent variables. The general formulation of the ARDL ( $p, q)$ model is:

$$
\begin{aligned}
& \Delta \mathrm{Y}_{\mathrm{it}}=\phi_{\mathrm{i}}\left(\mathrm{Y}_{\mathrm{i}, \mathrm{t}-1}-\mathrm{a}_{\mathrm{i}} \mathrm{X}_{\mathrm{i}, \mathrm{t}}\right)+\sum_{\mathrm{j}=1}^{\mathrm{p}-1} \theta_{\mathrm{i}, \mathrm{j}} \Delta \mathrm{Y}_{\mathrm{i}, \mathrm{t}-1}+\sum_{\mathrm{j}=0}^{\mathrm{p}-1} \delta_{\mathrm{i}} \Delta \mathrm{X}_{\mathrm{i}, \mathrm{t}-\mathrm{j}}+\omega_{\mathrm{i}} \\
& +\mu_{\mathrm{it}}
\end{aligned}
$$

where, i indicates cross-section group (i.e., country in this research), $\mathrm{t}$ indicates time (i.e., day in this research), $\mathrm{Y}$ is dependent variable, $\mathrm{X}$ is the vector of explanatory variables, $\omega$ indicates a 
Table 7

Estimates of the long-run impacts of mobility changes on $\mathrm{CO}$ emissions at the world level and by region.

\begin{tabular}{|c|c|c|c|c|c|c|c|c|c|c|}
\hline \multicolumn{2}{|c|}{ Independent variable } & \multicolumn{3}{|c|}{$\begin{array}{l}\text { Model } 1 \\
\text { Residential mobility }\end{array}$} & \multicolumn{3}{|l|}{$\begin{array}{l}\text { Model } 2 \\
\text { Transit mobility }\end{array}$} & \multicolumn{3}{|c|}{$\begin{array}{l}\text { Model } 3 \\
\text { Workplace mobility }\end{array}$} \\
\hline \multicolumn{2}{|c|}{ Dep. variable $\mathrm{D}(\mathrm{CO})$} & PMG & MG & DFE & PMG & MG & DFE & PMG & MG & DFE \\
\hline \multirow[t]{2}{*}{ All countries } & $\mathrm{EC}$ & $-.443 * * *(.031)$ & $-.519 * * *(.026)$ & $-.196 * * *(.013)$ & $-.439 * * *(.032)$ & $-.528 * * *(.028)$ & $-.196 * * *(.013)$ & $-.440 * * *(.030)$ & $-.511 * * *(.027)$ & $-.196 * * *(.012)$ \\
\hline & LR & $-.009 * * *(.002)$ & $-.058 * *(.020)$ & $-.060 * * *(.017)$ & $.003 * * *(.001)$ & $.021 * * *(.007)$ & $.025 * * *(.006)$ & $.004 * * *(.001)$ & $.023 * * *(.008)$ & $.026 * * *(.007)$ \\
\hline \multirow[t]{2}{*}{ South America } & $\mathrm{EC}$ & $-.460 * * *(.099)$ & $.512 * * *(.027)$ & $-.194 * * *(.013)$ & $-.454 * * *(.101)$ & $-.531 * * *(.075)$ & $-.410 * * *(.039)$ & $-.459 * * *(.003)$ & $-.521 * * *(.087)$ & $-409 * * *(.038)$ \\
\hline & LR & $-.022 * * *(.009)$ & $-.055 * * *(.020)$ & $-.053 * * *(.017)$ & $.008 * *(.003)$ & $.024 *(.012)$ & $.024 * * *(.006)$ & $.009 * * *(003)$ & $.027 * *(.013)$ & $.027 * * *(.006)$ \\
\hline \multirow[t]{2}{*}{ North America } & $\mathrm{EC}$ & $-.333 * * *(.124)$ & $-.356 * * *(.120)$ & $-.126 * * *(.037)$ & $-.318 * *(.126)$ & $-.349 * * *(.120)$ & $-.126 * * *(.037)$ & $-.050(.048)$ & $-.353 * * *(.122)$ & $-.127 * * *(.037)$ \\
\hline & LR & $-.014 * * *(.004)$ & $-.228(.217)$ & $-.221(.255)$ & $.004 * * *(.001)$ & $.073(.067)$ & $.069(.089)$ & $.258(.248)$ & $.096(.089)$ & $.095(.097)$ \\
\hline \multirow[t]{2}{*}{ US-Canada } & $\mathrm{EC}$ & $-.439 * * *(.109)$ & $-.462 * * *(.098)$ & $-.451 * * *(.077)$ & $-.417 * * *(.136)$ & $-.451 * * *(.109)$ & $-.441 * * *(.078)$ & $-.434 * * *(.131)$ & $-.456 * * *(.115)$ & $-.445 * * *(.078)$ \\
\hline & LR & $-.014 * * *(.004)$ & $-.017 * * *(.005)$ & $-.016 * * *(.004)$ & $.004 * * *(.001)$ & $.006 * * *(.002)$ & $.006 * * *(.001)$ & $.005 * * *(.002)$ & $.005 * * *(.002)$ & $.007 * * *(.002)$ \\
\hline \multirow[t]{2}{*}{ EU countries } & $\mathrm{EC}$ & $-.444 * * *(.057)$ & $-.472 * * *(.049)$ & $-.421 * * *(.040)$ & $-.450 * * *(.001)$ & $-.492 * * *(.049)$ & $-.427 * * *(.040)$ & $-.444 * * *(.056)$ & $-.473 * * *(.050)$ & $-.423 * * *(.040)$ \\
\hline & LR & $-.008 * * *(.001)$ & $-.013(.008)$ & $-.012 * * *(.005)$ & $.003 * * *(.001)$ & $.005(.003)$ & $.005 * * *(.002)$ & $.004 * * *(.006)$ & $.006 *(.003)$ & $.005 * * *(.002)$ \\
\hline \multirow[t]{2}{*}{ EU plus the UK } & $\mathrm{EC}$ & $-.462 * * *(.053)$ & $-.493 * * *(.047)$ & $-.440 * * *(.038)$ & $-.470 * * *(.001)$ & $-.513 * * *(.048)$ & $-.446 * * *(.038)$ & $-.462 * * *(.052)$ & $-.494 * * *(.049)$ & $-.441(.037)$ \\
\hline & LR & $-.008 * * *(.002)$ & $-.011(.008)$ & $-.010 * *(.004)$ & $.003 * * *(.000)$ & $.004(.002)$ & $.004 * * *(.001)$ & $.004 * * *(.001)$ & $.005 *(.001)$ & $.004 * *(.002)$ \\
\hline
\end{tabular}

Levels of significance: $* * *=1 \%, * *=5 \%$, and $*=10 \%$; Source: author's analysis; Cons. indicate Constant; figures outside and inside parentheses indicate coefficients and standard errors, respectively. $\mathrm{X}$ indicates specific mobility change as the independent variable. Source: authors' analysis.

constant, a represents the long-run elasticities, $\phi$ is the error correction term while $\delta$ and $\theta$ represent coefficients of short-run dynamics, $\mathrm{p}$ denotes lag of dependent variable, q denotes lag of independent variables, and $\mu$ is error term. In this research, mobility changes data for each of the six categories of places are used as explanatory variable (denoted $\mathrm{X}$ ) and $\mathrm{CO}$ emissions are used as dependent variable. The estimation of equation (1.0) is carried out separately for each of the six categories of places, constituting six different models.

The use of the PMG technique has several advantages as it can: (i) reveal the co-integrating coefficients for both the short-run and long-run separately, (ii) handle both stationary and non-stationary panels; the estimator can handle data that are stationary at either level or first difference or a combination of both, and (iii) mitigate endogeneity problems with the long-run coefficients by an autoregressive distributed lag approach (Pesaran and Smith 1995; Pesaran and Shin 1999; Pesaran et al., 1999; Blackburne and Frank 2007; Asteriou and Monastiriotis 2001). There are two other meangroup estimators often compared with PMG in the economic literature - the mean group (MG) and the dynamic fixed effect (DFE) estimators developed by Pesaran and Smith (1995), Pesaran and Shin (1999), Pesaran et al. (1999). The MG estimator estimates separate equations for each cross-section group (e.g., country) included and reports the mean of the estimates across groups; however, it overlooks that certain parameters may be the same across cross-section groups. The DFE estimator allows intercepts to differ across groups while considering all other coefficients and error variances to be the same. The PMG estimator is an intermediate between MG and DFE, which involves both pooling and averaging, and therefore considered as the most consistent and efficient one (Pesaran and Smith 1995; Simões 2011; Lee and Wang 2015). This paper produces and reports MG and DFE estimates in addition to PMG for comparison purpose and ensuring consistency and robustness of the overall results obtained.

\subsection{Data summary}

The list of 35 countries and their descriptive statistics by region are provided in appendix Table A2. Table 4 reports the descriptive statistics of all countries combined. As expected, largest average mobility declines for Transit stations, followed by Retail \& recreation and Workplace, while Residential mobility increase as people are forced to maintain social distancing measures through lock downs, movement restrictions, and stay home orders across the countries. Average CO emissions appear noticeably lower compared to its maximum value, reflecting the reduction of emissions across the globe.

Table 5 reports the correlation matrix, where the particular interest of this research is the correlation between $\mathrm{CO}$ emissions and mobility changes. As expected, significant and negative correlations exists between in indoor (i.e., Residential) mobility and CO emissions; correlations that between outdoor places and emissions are positive and significant, only except Park. It indicates a reduction in the pollutant's emissions as more people stay home.

\section{Results and discussion}

This section first discusses the trends and patterns of social distancing and $\mathrm{CO}$ emissions, followed by the discussion of the impacts of mobility changes on $\mathrm{CO}$ emissions.

\subsection{Trends and patterns of social distancing and CO emissions}

Fig. 1(a) and (b) report the trends and patterns of $\mathrm{CO}$ emissions across the countries. As expected and much discussed, during the pandemic period considered, average $\mathrm{CO}$ emissions across the countries show steep decline over time, particularly from the middle of March 2020 that continues in the later days. Over time, MECA countries remain the largest emitters, followed by the Americas. However, North America rather shows a volatile trend with a slightly increasing pattern, while emissions appear to have stable trend in Australia-New Zealand.

Fig. 2 shows mobility patterns for the six categories of places across the countries. The figure clearly shows a diverging pattern between mobility in Residential and that in other places, evidencing that mobility in Residential places has consistently increased over time while it has decreased in the other five outdoor places. This is expected given the reality of lockdowns and strict social distancing measures. The trend is consistent across regions for mobility in the six places, as shown in Fig. 3. However, East Asia and the Pacific appears to have relatively slower rates of mobility change to desired directions across almost all categories of places.

\subsection{Estimates of the impacts of mobility changes on $\mathrm{CO}$ emissions}

Before proceeding with estimation of impacts, it is necessary to check unit root of variables included. Appendix Tables A3 reports the results of the second-generation cross-section augmented dicky fuller (CADF) panel unit root test developed by Pesaran (2003). Results show that some variables are non-stationary at 


\begin{tabular}{|c|c|c|c|c|c|c|c|c|}
\hline \multicolumn{3}{|c|}{$\begin{array}{l}\text { Model } 4 \\
\text { Grocery \& pharma mobility }\end{array}$} & \multicolumn{3}{|c|}{$\begin{array}{l}\text { Model } 5 \\
\text { Retail \& recreation mobility }\end{array}$} & \multicolumn{3}{|l|}{$\begin{array}{l}\text { Model } 6 \\
\text { Park mobility }\end{array}$} \\
\hline PMG & MG & DFE & PMG & MG & DFE & PMG & MG & DFE \\
\hline$-.440 * * *(.030)$ & $-.499 * * *(.027)$ & $-.194 * * *(013)$ & $-.449 * * *(.031)$ & $-.533 * * *(.027)$ & $-.196 * * *(.012 \backslash 3)$ & $-.436 * * *(.033)$ & $-.521 * * *(.028)$ & $-.194 * * *(.013)$ \\
\hline $.004 * * *(.001)$ & $\begin{array}{l}.025 * * * \\
.(009)\end{array}$ & $.029 * * *(.009)$ & $.003 * * *(.001)$ & $.020 * * *(.007)$ & $.022 * * *(.006)$ & $.004 * * *(.001)$ & $.021 * * *(.007)$ & $.025 * * *(.007)$ \\
\hline$-.463 * * *(.104)$ & $-.517 * * *(.089)$ & $-.416 * * *(.039)$ & $-.453 * * *(.104)$ & $-.531 * * *(.078)$ & $-404 * * *(.039)$ & $-.453 * * *(.102)$ & $-.537 * * *(.076)$ & $-.400(.038)$ \\
\hline $.011 * *(.005)$ & $.029 *(.015)$ & $.034 * * *(.257)$ & $.007 *(.003)$ & $.023 * *(.012)$ & $.023 * * *(.006)$ & $.007 * *(.003)$ & $.025 *(.014)$ & $.024 * * *(.006)$ \\
\hline$-.290 * *(.124)$ & $-.293 * * *(.123)$ & $-.119 * * *(.036)$ & $-.344 * * *(.124)$ & $-.366 * * *(.121)$ & $-.126 * * *(.037)$ & $-.028(.033)$ & $-.329 * * *(.114)$ & $-.128 * * *(.037)$ \\
\hline $.005 *(.003)$ & $.089(.084)$ & $.052(.197)$ & $.005 * * *(.002)$ & $.075(.097)$ & $.073(.009)$ & $-.171(.509)$ & $.082(.073)$ & $.119(.127)$ \\
\hline$-.379 * * *(.149)$ & $-.379 * * *(.151)$ & $-.350 * * *(.074)$ & $-.454 * * *(.099)$ & $-.477 * * *(.084)$ & $-.449 * * *(.078)$ & $-.415 * * *(.111)$ & $-.422 * * *(.112)$ & $-.480 * * *(.058)$ \\
\hline $.004 * * *(.002)$ & $.004 *(.003)$ & $.005^{* * *}(.001)$ & $.005^{* * *}(.0020$ & $.006 * * *(.002)$ & $.006 * * *(.002)$ & $\begin{array}{l}.009 * * * \\
.002\end{array}$ & $.010 * * *(.002)$ & $.010 * * *(.003)$ \\
\hline$-.455 * * *(.057)$ & $-.479 * * *(.048)$ & $-.444 * * *(.040)$ & $.459 * * *(.057)$ & $-.502 * * *(.045)$ & $-.437 * * *(.039)$ & $-.458 * * *(.062)$ & $-.525 * * *(.066)$ & $-.445 * * *(.040)$ \\
\hline $.005 * * *(.001)$ & $.008 * * *(.005)$ & $.009 * * *(.002)$ & $.003 * * *(.001)$ & $.005(.003)$ & $.005 * * *(.001)$ & $.003 * * *(.001)$ & $.011 * *(.005)$ & $.006 * * * *(.001)$ \\
\hline$-.477 * * *(.054)$ & $-.504 * * *(.048)$ & $-.460 * * *(.038)$ & $-.477 * * *(.053)$ & $-.522 * * *(.044)$ & $.436 * * *(.038)$ & $-.480 * * *(.058)$ & $-.541 * * *(.059)$ & $-467 * * *(.038)$ \\
\hline $.004 * * *(.001)$ & $.007 *(.004)$ & $.008 * * *(.002)$ & $.003 * * *(.001)$ & $.004(.003)$ & $.004 * * *(.001)$ & $.003 * * *(.001)$ & $.009 * * *(.004)$ & $.006^{* * *}(.001)$ \\
\hline
\end{tabular}

level; however, all variables become stationary at first difference or order 1 , which satisfies the necessary requirement for mean-group estimations.

In order to implement the long-run and short-run estimations, appropriate lag order selection is essential. For lag order selection, first the using the AIC criteria optimal lag orders are obtained for each country. Applicable lag orders for the all-country and each regional panel are decided based on both mode and average of the lags available for countries in each panel. Appendix Table A4 reporting the lag orders suggest that for most panels including the all-countries, an optimal lag order of $(1,1)$ is suggested.

Using the lag orders specified, PMG, MG, and DFE estimations are carried out for all-countries and each panel for the six models. Table 6 reports the key estimation information for all panels. EC indicates the value of the error correction terms $(\phi)$ of each estimation. Results show that EC values are statistically significant and negative across all estimations, which suggest the existence of a long-run cointegrating relationship between mobility changes and CO emissions across the six models. Tables 7 and 8 report the PMG, MG, and DFE estimates of the long-run and short run impacts at the all-countries level and by region for each categories of places.

\subsubsection{Long-run impacts of mobility changes on CO emissions}

Table 7 reports the long-run estimates of the impacts of public mobility changes on CO emissions. The signs of coefficients for all outdoor and indoor places are consistent across the three estimators particularly for All-countries, US-Canada, EU including and excluding the UK, Other Europe, South America, and Middle East and Central Asia. Across these regions, impacts are consistently significant and negative for mobility changes in indoor places, while those are significant and positive for mobility changes in outdoor places.

Results suggest that LR coefficients are statistically significant and negative for Residential mobility across almost all the estimations. At the all-countries level, the long-run elasticity obtained by PMG estimation is $0.9 \%$. It suggests that an increased residential or indoor mobility changes in the long-run significantly reduces $\mathrm{CO}$ emissions. Since daily average residential mobility changes are positive (i.e., mobility grows or increases) during the period considered, the result indicates a reduction of $\mathrm{CO}$ emissions by about $0.9 \%$ due to a $1 \%$ rise in residential mobility increases. The result is consistent with the expectations about the benefits of strict lockdown and social distancing measures worldwide and the descriptive evidence suggested by the existing studies on $\mathrm{CO}$ emissions decline (e.g. Kanniah et al., 2020; Bashir et al., 2020; Islam et al., 2020).

Considering the PMG estimates of Residential mobility, Europe excluding the EU and the UK (8.4\%), East Asia and the Pacific (4.3\%),
Middle East and Central America (3.1\%), and South America (2.2\%) appear to have relatively larger and negative elasticity response to increases in Residential mobility. It indicates that these regions may have seen the biggest benefits in terms of decline in air pollution due to rises in indoor mobility increases. Further, both EU including and excluding UK show an elasticity of $-0.8 \%$. The results across the European panels are consistent with the available studies presenting descriptive evidence on the decline of $\mathrm{CO}$ emissions in European countries (e.g., Bilal et al., 2020; Cheval et al., 2020). The findings on East Asia and the Pacific and Middle East and Central Asia remain consistent with the available studies showing a large drop in CO emissions in different Asian countries (e.g., Islam et al., 2020; Wang and Su, 2020; Lokhandwala and Gautam, 2020; Gautam, 2020). According to the PMG estimates, CO emissions in US-Canada is elastic, i.e., a $1 \%$ rise in residential mobility increases decreases emissions by $1.4 \%$. The finding is consistent with the descriptive evidence of Bashir et al. (2020) on CO emissions decline in the US. Among others, Australia-New Zealand shows a long-run elasticity of $0.7 \%$ according to PMG estimations; however, the impact appears non-significant under MG and DFE estimations.

On the other hand, LR values are mostly significant and positive for mobility across all outdoor places, namely, Transit stations, Workplaces, Grocery \& pharmacy, Retail \& recreation, and Parks, contrary to the results of Residential mobility. This result suggests that increases in mobility across outdoor places significantly increases $\mathrm{CO}$ emissions. The result is consistent with the general expectation since increased mobility in outdoor places means increases in economic activities, resulting an increased level of pollutant emissions including $\mathrm{CO}$. Considering the PMG estimates at the all-countries level, $\mathrm{CO}$ emissions increase by about $0.2-0.4 \%$ in the long-run in response to a $1 \%$ rise in mobility increases across the five categories of outdoor places. Considering the regional level PMG estimates, Europe excluding the EU and the UK appear have larger increases (1.6-4.5\%) in CO emissions in response to a $1 \%$ rise in outdoor mobility changes across the six places, followed by Middle East and Central Asia (1.2-1.6\%). The long-run estimates for the outdoor places are not consistently significant across the estimators for North America (which includes Mexico), East Asia and the Pacific, South and Southeast Asia, and Australia-New Zealand. The results indicates to the dilution effect of Mexico as stated earlier since estimates are consistently significant and positive for North America excluding Mexico, i.e., US-Canada alone across the six models. Considering PMG estimates for US-Canada, the levels of $\mathrm{CO}$ emissions rise by $0.4-0.9 \%$ in response to a $1 \%$ rise in outdoor mobility increases across the five outdoor places.

Furthermore, results indicate that outdoor mobility increases do not increase $\mathrm{CO}$ emissions in a larger of Asia over the period 
Table 8

Estimates of the short-run impacts of mobility changes on CO emissions at the world level and by region.

\begin{tabular}{|c|c|c|c|c|c|c|c|c|c|}
\hline \multicolumn{2}{|c|}{ Independent variable } & \multicolumn{3}{|c|}{$\begin{array}{l}\text { Model } 1 \\
\text { Residential mobility }\end{array}$} & \multicolumn{3}{|l|}{$\begin{array}{l}\text { Model } 2 \\
\text { Transit mobility }\end{array}$} & \multicolumn{2}{|l|}{$\begin{array}{l}\text { Model } 3 \\
\text { Workplace } \\
\text { mobility }\end{array}$} \\
\hline \multicolumn{2}{|c|}{ Dep. variable $\mathrm{D}(\mathrm{CO})$} & PMG & MG & DFE & PMG & MG & DFE & PMG & MG \\
\hline \multirow[t]{2}{*}{ All countries } & $\mathrm{D} 1(\mathrm{X})$ & $-.013 * *(.006)$ & $-.001(.004)$ & $-.012(.009)$ & $.008(.006)$ & $-.001(.003)$ & $.012 * *(.006)$ & $.006 *(.003)$ & $.001(.001)$ \\
\hline & Cons. & $2.017 * * *(.274)$ & $2.687 * * *(.429)$ & $1.071 * * *(.090)$ & $1.934 * * *(.239)$ & $2.747 * * *(.439)$ & $1.102 * * *(.089)$ & $1.99 * * *(.269)$ & $2.612 * * *(.415)$ \\
\hline \multirow[t]{2}{*}{ South America } & $\mathrm{D} 1(\mathrm{X})$ & $-.008(.009)$ & $-.001(.004)$ & $-.012(.009)$ & $.001(.006)$ & $-.004(.005)$ & $.002(.011)$ & $.011(.007)$ & $.004(.006)$ \\
\hline & Cons. & $2.561 * * *(.755))$ & $2.648 * * *(.418)$ & $1.055 * * *(.087)$ & $2.475 * * *(.742)$ & $3.328 * * *(.823)$ & $2.403 * * *(.262)$ & $2.531 * * *(.779)$ & $3.280 * * *(.867)$ \\
\hline \multirow[t]{2}{*}{ North America } & $\mathrm{D} 1(\mathrm{X})$ & $-.002(.014)$ & $.015 * * *(.004)$ & $.008(.080)$ & $.007(.015)$ & $.003(.011)$ & $.009(.052)$ & $-.008 *(.052)$ & $-.009 * *(.004)$ \\
\hline & Cons. & $1.37 * * *(.082)$ & $1.80 * *(.856)$ & $1.262 * *(.567)$ & $1.339 *(.015)$ & $1.772 * *(.858)$ & $1.244 * *(.573)$ & $1.153(1.110)$ & $1.781 * *(.857)$ \\
\hline \multirow[t]{2}{*}{ US-Canada } & $\mathrm{D} 1(\mathrm{X})$ & $.011 * * *(.003)$ & $.012 * * *(.004)$ & $.009 *(.004)$ & $-.008 * *(.004)$ & $-.008 * *(.003)$ & $-.005(.003)$ & $-.005 * *(.002)$ & $-.005 * *(.002)$ \\
\hline & Cons. & $.889 * * *(.0210$ & $.949 * * *(.035)$ & $.970 * * *(.168)$ & $.817 * * *(.095)$ & $.915 * * *(.004)$ & $.944 * * *(.170)$ & $.861 * * *(.002)$ & $.924 * * *(.005)$ \\
\hline \multirow[t]{2}{*}{ EU countries } & $\mathrm{D} 1(\mathrm{X})$ & $-.004(.005)$ & $-.004(.005$ & $-.001(.004)$ & $-.000(.003)$ & $-.000(.003)$ & $-.002(.003)$ & $.001(.514)$ & $.001(.002)$ \\
\hline & Cons. & $1.156 * * *(.295)$ & $1.268 * * *(.307)$ & $1.120(.110)$ & $1.179 * * *(.307)$ & $1.338 * * *(.328)$ & $1.142 * * *(.110)$ & $1.160 * * *(.293)$ & $1.263 * * *(.303)$ \\
\hline \multirow[t]{2}{*}{ EU plus the UK } & $\mathrm{D} 1(\mathrm{X})$ & $-.004(.004)$ & $-.004(.005)$ & $-.001(.004)$ & $-.002(.003)$ & $-.003(.003)$ & $-.002(.003)$ & $.001(.001)$ & $.001(.001)$ \\
\hline & Cons. & $1.192 * * *(.259)$ & $1.297 * * *(.267)$ & $1.153 * * *(.103)$ & $1.217 * * *(.268)$ & $1.364 * * *(.284)$ & $1.176 * * *(.103)$ & $1.193 * * *(.257)$ & $1.294 * * *(.265)$ \\
\hline \multirow[t]{2}{*}{ Other Europe } & $\mathrm{D} 1(\mathrm{X})$ & $-.009(.006)$ & $-.005(.010)$ & $-.005(.033)$ & $.013(.010)$ & $.009(.007)$ & $.007(.012)$ & $.009 * *(.004)$ & $.006 * *(.003)$ \\
\hline & Cons. & $2.008^{* *}(.819)$ & $2.365^{* * *}(.703)$ & $2.042 * * *(.302)$ & $2.194 * *(.952)$ & $2.384 * * *(.796)$ & $2.041 * * *(.293)$ & $2.020 * *(.793)$ & $2.294 * * *(.677)$ \\
\hline
\end{tabular}

Levels of significance: $* * *=1 \%, * *=5 \%$, and $*=10 \%$; Source: author's analysis; Cons. indicate Constant; figures outside and inside parentheses indicate coefficients and standard errors, respectively. X indicates specific mobility change as the independent variable. Source: authors' analysis.

considered. Also, the dilution effects of including Mexico indicates that outdoor and indoor mobility changes may not significantly influence $\mathrm{CO}$ emissions, respectively, in the North American country. However, for East Asia and the Pacific region, estimated impacts are consistently significant across most of the estimations, as a consistent and significant impact is found for Residential and Transit mobility. It suggests that $\mathrm{CO}$ emissions in this region are primarily influenced by mobility in transit stations in the long-run. In the long-run according to the PMG estimates, a 1\% rise in travel and transit related mobility increases drive up $\mathrm{CO}$ emissions by $1.6 \%$ in the EAP region, while the same amount of rise in residential mobility increases significantly reduce emissions by $3.1 \%$.

In Table 7, looking by category of places, mobility changes in three places show the most significant and consistent long-run impacts on CO emissions - Residential, Transit stations, and Workplaces across the regions, where increased indoor or residential mobility lowers emissions and increased transit and workplace mobility drives up emissions. The findings are in line with the fact that fossil fuel (e.g., natural gas, oil, coal, and wood) burning vehicular movement primarily for short and long distance travelling and transports and production activities in plants and factories are the largest contributor to $\mathrm{CO}$ emissions globally (Voiland 2015, June 1; TRB and NRC 2002).

Across all panels, the significance of coefficient estimates across all three - PMG, MG, and DFE - estimators for each model confirm the robustness and consistency of the long-run impacts of mobility changes on $\mathrm{CO}$ emissions.

\subsubsection{Short-run impacts of mobility changes on CO emissions}

Table 8 reports the short-run impacts of mobility changes in the six categories of places on $\mathrm{CO}$ emissions. The table shows limited short-run effects of mobility changes across the places. At the all-countries level and across most regions, there is no consistent evidence of a significant short-run effect of mobility changes on $\mathrm{CO}$ emissions. While for some panels significant impacts are shown by one or two specific estimators, however, they cannot be consistently confirmed across the estimators. Albeit, a significant and positive effect of Residential mobility on CO emissions is evident. The result seems in contrast to the general expectation; yet, it could reflect the increased emissions caused by an increased hours of usage of fuel-burning household appliances during the lockdown such as clothes dryers, water heaters, furnaces or boilers, fireplaces, both gas and wood burning, gas stoves and ovens, grills, generators, power tools, lawn equipment, wood stoves, and gas-fired central heating (MHD 2017; Saidur et al., 2009). There is further evidence that increased workplace mobility in US-Canada significantly increases $\mathrm{CO}$ emissions in the short-run in addition to the long-run.

Considering the results reported in Tables 7 and 8, it is evident that mobility changes have a significant impact on CO emissions predominantly in the long-run. In other words, mobility changes significantly affect the level of air pollution or air quality through $\mathrm{CO}$ emissions mainly in the long-run. The results and findings are broadly robust and consistent across all three different estimators used.

Findings overall empirically support the increased level of discussion on the air quality benefits of strict social distancing and lockdown measures due to COVID-19. This research calls for rethinking policies to reduce outdoor mobility in highly polluting means in the post-pandemic world. While reducing public mobility be hard as it is likely to reduce economic activities, finding out mechanisms that encourage reduced mobility in highly polluting means (e.g., vehicular movement) while keeping economic activities unaffected is important. One such possibility is work-fromhome approach that has recently become popular because of COVID-19. A sudden shift towards work-from-home and its productivity benefits with the help of technology encourages many companies across the world to continue it even in the postpandemic period. Such permanent nature of shift in the long-run could significantly help in reducing environmental pollution, in particular air pollution.

While the findings of this research provide important implications, future research could consider alternative measures to extend the findings of this research that can better capture the degree of strictness of lockdowns. For example, further research could consider the lockdown stringency index developed by the University of Oxford to measure real public mobility changes (Hale et al., 2020). Forthcoming research could consider examining the mediating role of technology on the effects of lockdowns and mobility restrictions on environmental pollution. In addition, follow up research could examine the association between $\mathrm{CO}$ variation and the number of deaths due to COVID-19. 


\begin{tabular}{|c|c|c|c|c|c|c|c|c|c|}
\hline \multirow{2}{*}{$\begin{array}{l}\text { Model } 3 \\
\text { Workplace } \\
\text { mobility } \\
\text { DFE }\end{array}$} & \multicolumn{3}{|c|}{$\begin{array}{l}\text { Model } 4 \\
\text { Grocery \& pharma mobility }\end{array}$} & \multicolumn{3}{|c|}{$\begin{array}{l}\text { Model } 5 \\
\text { Retail \& recreation mobility }\end{array}$} & \multicolumn{3}{|l|}{$\begin{array}{l}\text { Model } 6 \\
\text { Park mobility }\end{array}$} \\
\hline & PMG & MG & DFE & PMG & MG & PMG & & MG & DFE \\
\hline $.004(.003)$ & $-.004(.006)$ & $-.009(.009)$ & $.003(.003)$ & $.007(.005)$ & $.002(.004)$ & $.010 * *(.005)$ & $\begin{array}{l}.006 * * \\
(.003)\end{array}$ & $.002(.002)$ & $.002(.002)$ \\
\hline $1.057 * * *(.085)$ & $1.997 * * *(.284)$ & $2.506 * * *(.459)$ & $\begin{array}{l}.995 * * * \\
(.080)\end{array}$ & $2.044 * * *(.278)$ & $2.735 * * *(.436)$ & $1.070 * * *(.088)$ & $\begin{array}{l}2.004 * * * \\
(.281)\end{array}$ & $\begin{array}{l}2.604 * * * \\
(.406)\end{array}$ & $\begin{array}{l}1.016^{* * * *} \\
(.078)\end{array}$ \\
\hline $.002(.008)$ & $.006(.006)$ & $.002(.006)$ & $.003(.008)$ & $.014 *(.009)$ & $\begin{array}{l}.009 \\
.006\end{array}$ & $.012(.012)$ & $.017(.011)$ & $.011(.007)$ & $\begin{array}{l}.006 \\
.010\end{array}$ \\
\hline $2.362 * * *(.255)$ & $2.522 * * *(.763)$ & $3.184 * * *(.859)$ & $\begin{array}{l}2.385 * * * \\
(.257)\end{array}$ & $2.479 * * *(.759)$ & $3.329 * * *(.825)$ & $2.390 * * *(.266)$ & $\begin{array}{l}2.455 * * * \\
(.747)\end{array}$ & $\begin{array}{l}3.338 * * * \\
(.823)\end{array}$ & $\begin{array}{l}2.367 * * * \\
(.270\end{array}$ \\
\hline$-.005(.028)$ & $-.064(.065)$ & $-.068(.069)$ & $-.016(.039)$ & $.034(.032)$ & $.030(.028)$ & $.021(.052)$ & $.011(.012)$ & $.006(.009)$ & $-.007(.028)$ \\
\hline $1.272 * *(.548)$ & $1.163 * *(.472)$ & $1.273 * *(.583)$ & $\begin{array}{l}.978 * * \\
(.453)\end{array}$ & $1.433 * * *(.520)$ & $1.838 * *(.859)$ & $1.223 * *(.545)$ & $.509(.519)$ & $1.640 *(.857)$ & $\begin{array}{l}1.097 * * \\
(.455)\end{array}$ \\
\hline$-.003 *(.002)$ & $.001(.001)$ & $.001(.002)$ & $.000(.002)$ & $.002(.001)$ & $.002(.002)$ & $.001(.003)$ & $-.003(.003)$ & $-.003(.002)$ & $-.004(.001)$ \\
\hline $.954 * * *(.168)$ & $.696^{* * *}(.117)$ & $.695 * * *(.121)$ & $\begin{array}{l}.705 * * * \\
(.152)\end{array}$ & $.919 * * *(.014)$ & $.980 * * *(.073)$ & $.956 * * *(.169)$ & $\begin{array}{l}.769 * * * \\
(.011)\end{array}$ & $.783 * * *(.011)$ & $\begin{array}{l}.816^{* * * *} \\
(.141)\end{array}$ \\
\hline $.000(.002)$ & $-.003(.002)$ & $-.003 *(.002)$ & $-.002(.001)$ & $-.004 *(.002)$ & $-.005 * *(.002)$ & $-.004(.002)$ & $.000(.001)$ & $-.002(.002)$ & $-.000(.001)$ \\
\hline $1.129 * * *(.110)$ & $1.191 * * *(.306)$ & $1.305 * * *(.322)$ & $\begin{array}{l}1.178 * * * \\
(.108)\end{array}$ & $1.193 * * *(.300)$ & $1.375^{* * *}(.326)$ & $1.173 * * *(.110)$ & $\begin{array}{l}1.182 * * * \\
(.316)\end{array}$ & $1.44 * * *(.389)$ & $\begin{array}{l}1.134 * * * \\
(.105)\end{array}$ \\
\hline $.000(.002)$ & $-.004 *(.002)$ & $-.005^{* *}(.002)$ & $-.002 *(.002)$ & $-.005 * *(.002)$ & $-.005^{* * *}(.002)$ & $-.004(.002)$ & $-.000(.001)$ & $-003(.002)$ & $-.001(.001)$ \\
\hline $1.160 * * *(.103)$ & $1.231 * * *(.268)$ & $1.343 * * *(.282)$ & $1.206 * * *(.101)$ & $1.228 * * *(.263)$ & $1.400 * * *(.284)$ & $1.196 * * *(.102)$ & $1.227 * * *(.277)$ & $\begin{array}{l}1.457 * * * \\
(.377)\end{array}$ & $\begin{array}{l}1.183 * * * \\
(.099)\end{array}$ \\
\hline $.010(.009)$ & $.008(.007)$ & $.002(.008)$ & $-.004(.008)$ & $-.003(.009)$ & $-.006(.0$ & $006) \quad-.007(.011)$ & $.003(.002)$ & $-.003(.006)$ & $-.003(.006)$ \\
\hline $1.954 * * *(.288)$ & $1.711 * * *(.551)$ & $1.947 * * *(.534)$ & $1.750 * * *(.264)$ & $2.19 * *(.925)$ & $2.439 * * *$ & $*(.755) 2.042 * * *(.292)$ & $1.849 * * *(.493)$ & $2.167(.568)$ & $\begin{array}{l}1.964 * * * \\
(.270)\end{array}$ \\
\hline
\end{tabular}

\section{Conclusion}

This paper examines the long-run and short-run impacts of mobility changes in six broad categories of indoor and outdoor places on CO emissions - one of the main air pollutants - using a panel of 35 countries over a period of COVID-19. Findings suggest that mobility changes in all categories of indoor and outdoor places have a significant long-run impact on $\mathrm{CO}$ emissions at the allcountries level and across regions. In the long-run, indoor or residential mobility increases significantly reduce $\mathrm{CO}$ emissions, while outdoor mobility increases, particularly in transit stations and workplaces, significantly increase CO emissions. Across regions, a relatively larger magnitude of emission impact of mobility changes is found for Europe excluding the EU and the UK. While no consistent evidence of short-run impacts is found, US-Canada is the only region showing that workplace mobility increases raise $\mathrm{CO}$ emissions in both the short and long run. Findings overall provides a reminder about the need for reducing unnecessary and polluting means of outdoor activities with the help of the advancing technologies. The paper thus highlights the need for leveraging the advanced technologies across the board that help to enhance or maintain a similar level of productivity by working more from home. Compared to others region, a greater sensitivity of Europe, US and Canada provides a significant information about the extent of benefits the regions could achieve by reducing outdoor mobility with the help of technology. The findings however could be subject to few limitations; for example, Google data used may not appropriately represent real public mobility changes. In this context, scholars could also consider systematic ways to measure mobility changes by the Oxford COVID-19 government response tracker (OxCGRT).

\section{CRediT authorship contribution statement}

Suborna Barua: Conceptualization, Data curation, Formal analysis, Investigation, Methodology, Resources, Software, Visualization, Writing - original draft. Shobod Deba Nath: performed the roles of Literature review, Theoretical background development, Writing - original draft.

\section{Declaration of competing interest}

The authors declare that they have no known competing financial interests or personal relationships that could have appeared to influence the work reported in this paper.

\section{Appendix A. Supplementary data}

Supplementary data to this article can be found online at https://doi.org/10.1016/j.jclepro.2021.126755.

\section{References}

Asteriou, D., Monastiriotis, V., 2001. Trade Unionism and Growth: A Panel Data Study. University of Reading, Henley Business School. Discussion Paper 429.

Baldwin, R., di Mauro, B.W. (Eds.), 2020. Economics in the Time of COVID-19, first ed. CEPR Press, London.

Barua, S., 2020a. COVID-19 pandemic and world trade: some analytical notes. Working Paper. Available at: https://ssrn.com/abstract=3577627.

Barua, S., 2020b. Understanding coronanomics: the economic implications of the coronavirus (COVID-19) pandemic. J. Develop. Areas. Accepted Manuscript (Forthcoming). Draft available at: https://doi.org/10.2139/ssrn.3566477.

Barua, B., Barua, S., 2021. COVID-19 implications for banks: evidence from an emerging economy. SN Business Econ. 1 (1), 1-28, 19. https://doi.org/10.1007/ S43546-020-00013-W.

Bashir, M.F., Ben Jiang, M.A., Bilal, Komal, B., Bashir, M.A., Farooq, T.H., Iqbal, N., Bashir, M., 2020. Correlation between environmental pollution indicators and COVID-19 pandemic: a brief study in Californian context. Environ. Res. 187, 109652 https://doi.org/10.1016/j.envres.2020.109652.

Bilal, Bashir, M.F., Benghoul, M., Numan, U., Shakoor, A., Komal, B., Bashir, M.A., Bashir, M., Tan, D., 2020. Environmental pollution and COVID-19 outbreak: insights from Germany. Air Qual. Atmos. Health 13, 1385-1394. https://doi.org/ 10.1007/s11869-020-00893-9.

Blackburne, E.F., Frank, M.W., 2007. Estimation of nonstationary heterogeneous panels. STATA J. 7 (2), 197-208.

6 May CDC, 2020. Social Distancing: Keep Your Distance to Slow the Spread. Center for Disease Control and Prevention. https://www.cdc.gov/coronavirus/2019ncov/prevent-getting-sick/social-distancing.html. (Accessed 10 May 2020).

Cheval, S., Mihai, A.C., Georgiadis, T., Herrnegger, M., Piticar, A., Legates, D.R., 2020. Observed and potential impacts of the COVID-19 pandemic on the environment. Int. J. Environ. Res. Publ. Health 17 (11), 4140. https://doi.org/10.3390/ ijerph17114140.

March 19 ESA, 2020a. COVID-19: Nitrogen Dioxide over China, 2020. http://www. esa.int/Applications/Observing_the_Earth/Copernicus/Sentinel-5P/COVID-19_ nitrogen_dioxide_over_China. (Accessed 8 May 2020).

April 16 ESA, 2020b. Air Pollution Remains Low as Europeans Stay at Home, 2020. https://www.esa.int/Applications/Observing_the_Earth/Copernicus/Sentinel5P/Air_pollution_remains_low_as_Europeans_stay_at_home. (Accessed 8 May 
2020)

ESA, 2020c. Air Pollution Drops in India Following Lockdown European Space Agency. April 24. European Space Agency. https://phys.org/news/2020-04-airpollution-india-lockdown.html. (Accessed 19 May 2020).

Gautam, S., 2020. COVID-19: air pollution remains low as people stay at home. Air Qual. Atmos. Health 13, 853-857. https://doi.org/10.1007/s11869-020-00842-6.

Google, L.L.C., 2020. Google COVID-19 Community Mobility Reports. Retrieved 2 May 2020 from. https://www.google.com/covid19/mobility/.

Hale, T., Angrist, N., Boby, T., Cameron-Blake, E., Hallas, L., Kira, B., Majumdar, S., Petherick, A., Phillips, T., Tatlow, H., Webster, S., 2020. Variation in Government Responses to COVID-19. BSG Working Paper 2020/032, University of Oxford (December). Retrieved 22 January 2021 from. https://www.bsg.ox.ac.uk/sites/ default/files/2020-12/BSG-WP-2020-032-v10.pdf.

He, G., Pan, Y., Tanaka, T., 2020. The short-term impacts of COVID-19 lockdown on urban air pollution in China. Nat. Sustain. https://doi.org/10.1038/s41893-0200581-y.

Henriques, M., 2020. Will Covid-19 Have a Lasting Impact on the Environment? BBC Futures. March 27. Retrieved from. https://www.bbc.com/future/article/ 20200326-covid-19-the-impact-of-coronavirus-on-the-environment.

Islam, M.S., Tusher, T.R., Roy, S., Rahman, M., 2020. Impacts of nationwide lockdown due to COVID-19 outbreak on air quality in Bangladesh: a spatiotemporal analysis. Air Qual Atmos Health. https://doi.org/10.1007/s11869-020-00940-5. Early view available at.

Kanniah, K.D., Zaman, N.A.F.K., Kaskaoutis, D.G., Latif, M.T., 2020. COVID-19's impact on the atmospheric environment in the Southeast Asia region. Sci. Total Environ. 736, 139658.

Le Quéré, C., Jackson, R., Jones, M., Smith, A., Abernethy, S., Andrew, R., De-Gol, A., et al., 2020. Temporary reduction in daily global $\mathrm{CO} 2$ emissions during the COVID-19 forced confinement. Nat. Clim. Change. https://doi.org/10.1038/ s41558-020-0797-x.

Lee, Y., Wang, K., 2015. Dynamic heterogeneous panel analysis of the correlation between stock prices and exchange rates. Econ. Res.- Ekonomska Istraživanja 28 (1), 749-772.

Lin, B., Zhu, J., 2018. Changes in urban air quality during urbanization in China. J. Clean. Prod. 188, 312-321.

Lokhandwala, S., Gautam, P., 2020. Indirect impact of COVID-19 on environment: a brief study in Indian context. Environ. Res. 188, 109807. https://doi.org/10.1016/ j.envres.2020.109807.

McGrath, M., 2020. Coronavirus: Five Charts about the Biggest Carbon Crash. May 6. https://www.bbc.com/news/science-environment-52485712. (Accessed 8 May 2020).

MHD, 2017. Carbon Monoxide: Preventing Carbon Monoxide Poisoning in Your Home. Minnesota Health Department, Indoor Air Unit, United States of America.

Monks, P., 2020. Here's How Lockdowns Have Improved Air Quality Around the World. April 20. World Economic Forum. Retrieved 8 May 2020, from. https:// www.weforum.org/agenda/2020/04/coronavirus-lockdowns-air-pollution.

Muhammad, S., Long, X., Salman, M., 2020. COVID-19 pandemic and environmental pollution: a blessing in disguise? Sci. Total Environ. 728, 138820.

NASA, 2020. NASA Satellite Data Show 30 Percent Drop in Air Pollution over Northeast U.S. National Aeronautical and Space Authority. April 10. https://www. nasa.gov/feature/goddard/2020/drop-in-air-pollution-over-northeast/. (Accessed 19 May 2020).

Nicola, M., Alsafi, Z., Sohrabi, C., Kerwan, A., Al-Jabir, A., Iosifidis, C., Agha, M., Agha, R., 2020. The socio-economic implications of the coronavirus and COVID-
19 pandemic: a review, 30316-2 Int. J. Surg. 20, S1743-S9191. London, England.

Patel, K., 2020. March 5) how the coronavirus is (and is not) affecting the environment. Earth Observatory Blog. NASA. Retrieved from. https:// earthobservatory.nasa.gov/blogs/earthmatters/2020/03/05/how-thecoronavirus-is-and-is-not-affecting-the-environment/.

Penney, D., Benignus, V., Kephalopoulos, S., Kotzias, D., Kleinman, M., Verrier, A 2010. Carbon monoxide. In: WHO Guidelines for Indoor Air Quality: Selected Pollutants. World Health Organization, Geneva, 2010 (2).

Pesaran, H., 2003. A simple panel unit root test in the presence of cross section dependence. Cambridge Working Papers in Economics 0346. University of Cambridge.

Pesaran, M.H., Shin, Y., 1999. An autoregressive distributed lag modelling approach to cointegration analysis. In: Strom, S. (Ed.), Econometrics and Economic Theory in the 20th Century. Cambridge University Press (Chapter 11).

Pesaran, M.H., Shin, Y., Smith, R.P., 1999. Pooled mean group estimation of dynamic heterogeneous panels. J. Am. Stat. Assoc. 94, 621-634.

Pesaran, M.H., Smith, R.P., 1995. Estimating long-run relationships from dynamic heterogeneous panels. J. Econom. 68, 79-113.

Rume, T., Islam, S.M.D., 2020. Environmental effects of COVID-19 pandemic and potential strategies of sustainability. Heliyon 6 (9), e04965. https://doi.org/ 10.1016/j.heliyon.2020.e04965.

Saidur, R., Sattar, M.A., Masjuki, H.H., Jamaluddin, M.Y., 2009. Greenhouse gas emissions from refrigeration equipment in Malaysia. Energy Environ. 20 (4), $533-551$.

Simões, M.C.N., 2011. Education composition and growth: a pooled mean group Analysis of OECD countries. Panoeconomicus 4, 455-471.

TRB, N.R.C., 2002. The Ongoing Challenge of Managing Carbon Monoxide Pollution in Fairbanks, Alaska: Interim Report. The National Academies Press, Washington, DC. Transportation Research Board and National Research Council.

UNDP, 2020. The economic and social impact of COVID-19 in the Asia-Pacific region. Position Note. UNDP Regional Bureau for Asia and the Pacific. April.

Voiland, A., 2015. June 1) Fourteen years of carbon monoxide from MOPITT. NASA's Earth Observatory. National Aeronautical and Space Authority. https://climate. nasa.gov/news/2291/fourteen-years-of-carbon-monoxide-from-mopitt/. (Accessed 18 May 2020).

Wang, Q., Su, M., 2020a. A preliminary assessment of the impact of COVID-19 on environment - a case study of China, 2020 Sci. Total Environ. 728, 138915.

Watts, J., 2020. Climate Crisis: in Coronavirus Lockdown, Nature Bounces Back - but for How Long? the Guardian. April 9. https://www.theguardian.com/world/ 2020/apr/09/climate-crisis-amid-coronavirus-lockdown-nature-bounces-backbut-for-how-long.

WHO, 2020. Coronavirus disease (COVID-19) advice for the public, 29 April. https:// www.who.int/emergencies/diseases/novel-coronavirus-2019/advice-for-public. (Accessed 10 May 2020).

WTO, 2020. Trade Statistics and Outlook. Press Release. World Trade Organization.

Yang, C.Y., Chen, Y.S., Yang, C.H., Ho, S.C., 2004. Relationship between ambient air pollution and hospital admissions for cardiovascular diseases in Kaohsiung, Taiwan. J. Toxicol. Environ. Health A 67 (6), 483-493. https://doi.org/10.1080/ 15287390490276502

Yang, T., Liu, W., 2018. Does air pollution affect public health and health inequality? Empirical evidence from China. J. Clean. Prod. 203, 43-52.

Zhang, H., Wang, S., Hao, J., Wang, X., Wang, S., Chai, F., Li, M., 2016. Air pollution and control action in Beijing. J. Clean. Prod. 112 (2), 1519-1527. 